\title{
TIME INCONSISTENCY AND FREE-RIDING IN A MONETARY UNION
}

\author{
V. V. Chari \\ Patrick J. Kehoe \\ Working Paper 9370 \\ http://www.nber.org/papers/w9370 \\ NATIONAL BUREAU OF ECONOMIC RESEARCH \\ 1050 Massachusetts Avenue \\ Cambridge, MA 02138 \\ December 2002
}

The views expressed herein are those of the authors and not necessarily those of the Federal Reserve Bank of Minneapolis, the Federal Reserve System, or the National Bureau of Economic Research.

(C) 2002 by V. V. Chari and Patrick J. Kehoe. All rights reserved. Short sections of text, not to exceed two paragraphs, may be quoted without explicit permission provided that full credit, including (C) notice, is given to the source. 
Time Inconsistency and Free-Riding in a Monetary Union

V. V. Chari and Patrick J. Kehoe

NBER Working Paper No. 9370

December 2002

JEL No. F3, F31, F33, F34, E4, E42, E58, E61, E63

\section{$\underline{\text { ABSTRACT }}$}

We analyze the setting of monetary and nonmonetary policies in monetary unions. We show that in these unions a time inconsistency problem in monetary policy leads to a novel type of freerider problem in the setting of nonmonetary policies, such as labor market policy, fiscal policy, and bank regulation. The free-rider problem leads the union's members to pursue lax nonmonetary policies that induce the monetary authority to generate high inflation. The free-rider problem can be mitigated by imposing constraints on the nonmonetary policies, like unionwide rules on labor market policy, debt constraints on members' fiscal policy, and unionwide regulation of banks. When there is no time inconsistency problem, there is no free-rider problem, and constraints on nonmonetary policies are unnecessary and possibly harmful.

\author{
V. V. Chari \\ Department of Economics \\ University of Minnesota \\ Minneapolis, MN 55455 \\ and Federal Reserve Bank of Minneapolis \\ and NBER \\ chari@res.mpls.frb.fed.us
}

\author{
Patrick J. Kehoe \\ Research Department \\ Federal Reserve Bank of Minneapolis \\ 90 Hennepin Avenue \\ Minneapolis, MN 55480 \\ and University of Minnesota \\ and NBER \\ pkehoe@res.mpls.frb.fed.us
}


In the last decade, there has been growing interest in the design of monetary unionsgroups of political units (countries or states or provinces) that have a great deal of independence in setting fiscal and other nonmonetary policies, but that share a central monetary authority, which sets a single monetary policy for all the members of the union. In practice, some monetary unions have worked poorly while others have worked well. Argentina is an example of an unsuccessful one; the United States, a successful one; and the jury is still out on the European Union. Why are some monetary unions successful and others not? Here we develop a theory that answers this question.

The time inconsistency problem in monetary policy is at the heart of our theory. We argue that this monetary policy problem leads to a free-rider problem in the setting of nonmonetary policies. Free-riding union members pursue inefficiently lax nonmonetary policies that benefit them individually, but that induce the monetary authority to generate high inflation. One way to eliminate both problems is to directly solve the time inconsistency problem in monetary policy. As is well-known, this problem can be eliminated with either commitment or reputational mechanisms. When either type of mechanism is in place, there is no free-rider problem, so that solving the time inconsistency problem indirectly eliminates the free-rider problem. In practice, of course, it is difficult to change the degree of effective commitment, say, by developing a reputation. For our purposes, we will take as given whether or not a monetary authority has a time inconsistency problem.

More interestingly, solving the free-rider problem helps mitigate the time inconsistency problem in monetary policy. The free-rider problem can be solved by imposing constraints on nonmonetary policies, such as unionwide rules on labor market policies, debt constraints on fiscal policy, and unionwide regulation of banks.

We first make these points in a general theoretical setup. Our setup has governments who set nonmonetary policies noncooperatively, competitive private agents and a benevolent monetary authority that chooses inflation. The monetary authority's optimal inflation rate 
depends on the decisions of private agents and on the nonmonetary policies. Private agents make their decisions anticipating the choice of the monetary authority. Governments choose their nonmonetary policies anticipating the choices of both private agents and the monetary authority.

We show that the free-rider problem in our setup is quite different from those in the literature. In the standard free-rider problem the agents are directly linked because the actions of each agent directly affect the payoffs of other agents. We have no such direct links. In our setup the nonmonetary policies of the governments affect the common inflation rate and thus indirectly affect the payoffs of other governments. One might think that this indirect link suffices to generate a free-rider problem. It does not because of an envelope argument: the monetary authority chooses inflation optimally so that, at the margin, an incremental change in inflation has no effect on welfare. Thus, when a government is contemplating a change in its nonmonetary policies away from the cooperative benchmark, the induced effects of its policies on the welfare of other countries is zero.

In our setup forward-looking private agents are the source of the free-rider problem. A change in government policy in some country makes the private agents in all the countries predict a change in inflation, and this predicted change makes them change their actions. Because each government cares about the decisions of its private agents, a change in government policy in any country affects welfare in all countries. This indirect link results in a free-rider problem. If private agents' decisions do not depend on their forecasts of inflation then this link is broken and there is no free-rider problem. Of course, if private agents' decisions do not depend on their forecasts of inflation then there is no time inconsistency problem to begin with.

With commitment by the monetary authority, the setting of nonmonetary policies does not induce changes in the inflation rate, and there is no free-rider problem. Thus, the presence or absence of a free-rider problem in nonmonetary policies is intimately connected 
to the time inconsistency problem of monetary policy.

After detailing this theory, we consider applications to three types of nonmonetary policies: labor market policy, fiscal policy, and bank regulation.

We first apply our theory to labor market policy. To do so, we modify the classic model of time inconsistency in monetary policy (due to Kydland and Prescott (1977) and Barro and Gordon (1983)). In our modification of this classic model, governments determine the natural rate of unemployment by their setting of labor market policies. We show that the free-rider problem leads governments to adopt policies that result in excessively high unemployment and inflation.

We then apply our theory to fiscal policy. We consider a simple dynamic model with many countries united in a monetary union. Each country's fiscal authority issues nominal debt to outside risk-neutral lenders. After that, the union's monetary authority decides on the common inflation rate. The monetary authority balances inflation's benefits (devalued nominal debt) against its costs (lower output). The larger the debt the monetary authority inherits, the higher it sets the inflation rate.

The fiscal authorities balance the consumption-smoothing gains from issuing debt against the induced costs of higher inflation on their own output. Each country's fiscal authority ignores the induced costs of inflation on output in other countries. Thus, relative to a cooperative benchmark, each fiscal authority issues too much debt, which leads the monetary authority to create too much inflation, which in turn leads to an inefficiently low level of output for all members of the union.

If there is some mechanism through which the monetary authority can effectively commit to its policy, then there is no free-rider problem. In practice, though, such commitment is often not available, and monetary unions have typically chosen to attack the free-rider problem directly. One way of doing so is to impose constraints on the amount of debt that the union members can issue. In our example, appropriately chosen constraints solve the 
free-rider problem.

Finally, we apply our theory to bank regulation. We develop a simple dynamic banking model with many countries united in a monetary union. Each country's government regulates the riskiness of banks' portfolios. When banks cannot fully pay off depositors, the monetary authority prints money to pay the residual amount, thus increasing inflation. Each government balances the costs of bank regulation against the induced costs of inflation resulting from bank bailouts. In doing so, the governments ignore the induced costs of inflation on other members of the union. These forces thus generate a free-rider problem in which regulation of banks is lax, bank bailouts are too frequent, and the rate of inflation is excessive, all compared to efficient levels. If there is no mechanism available to solve the time inconsistency problem directly, then the free-rider problem in this model can be mitigated with mutually agreed upon constraints on bank regulation.

Why are some monetary unions successful and others not? Our theory suggests that monetary unions are likely to fail when there is a time inconsistency problem in monetary policy and constraints on nonmonetary policies are either not present or not effective.

Argentina is an example of a monetary union which has a serious time inconsistency problem with its monetary policy and which, regardless of its good intentions, is unable to set effective constraints on its members. Argentina's provincial governments routinely run budget deficits that end up being financed by the central bank. Nicolini et al. (2000) demonstrate that Argentina's monetary authority has routinely bailed out the provincial governments when they have run into fiscal difficulties. Now bailouts are expected, which has increased the provinces' incentives to behave imprudently. Indeed, one rationalization of the convertibility law which linked Argentina's peso to the U.S. dollar is the hope of restraining the financial profligacy of provincial governments. Jones et al. (2000) show some evidence that provincial fiscal deficits fell after the imposition of convertibility, though the recent collapse of the currency board suggests that the time inconsistency problems in monetary 
policy are still present. For related discussions of Argentina, see the work of Cooper and Kempf (2001a and b) and Tommasi et al. (2001).

The United States is an example of a successful monetary union. This union of states appears to have solved the time inconsistency problem in monetary policy, so that there is no free-rider problem.

The success of the European Monetary Union is not yet clear. Our theory provides one rationale for the fiscal policy restrictions in the treaty establishing this union (the Maastricht Treaty) and in the recent Stability and Growth Pact among its members. One reading of the Maastricht Treaty, notwithstanding the solemn expressions of intent of the primacy of price stability, is that monetary policy is to be set sequentially by majority rule. As such, the time inconsistency problem in monetary policy is potentially severe. In such a scenario, our analysis shows that debt constraints are desirable. Our analysis is consistent with the view that the framers of the Maastricht Treaty thought commitment to monetary policy was extremely difficult to achieve and therefore wisely included debt constraints as an integral part of the treaty and the pact.

An alternative reading of the Maastricht Treaty is that the primacy of the goal of price stability and the independence of the central bank effectively ensure commitment to monetary policy and thereby solve the time inconsistency problem. Under this readingas our analysis with commitment indicates - debt constraints are unnecessary and possibly harmful. (For a forceful argument that debt constraints are harmful, see Buiter et al.'s 1993 work.)

Other monetary unions could be investigated. In fact, Von Hagen and Eichengreen (1996) assemble data on fiscal policy restrictions in 49 countries. Interestingly, they find that 37 of these countries impose restrictions on the fiscal policies of their subcentral governments. This finding suggests that, in practice, policymakers are concerned with fiscal profligacy of the subcentral governments and have adopted measures to constrain such behavior. 
Our research here is related to a literature on fiscal policy in monetary unions, including Giovannini and Spaventa (1991), Sibert (1992), Beetsma and Uhlig (1999), Cooper and Kempf (2001c), Dixit and Lambertini (2001), and Uhlig (2002). Those most closely related to our work here are Cooper and Kempf's and Uhlig's work. Cooper and Kempf focus mostly on the gains to monetary union with commitment by the monetary authority and show that without commitment, the monetary union may be undesirable. Uhlig develops a reducedform model in which there is a free-rider problem in fiscal policy. This free-rider problem ends up reducing welfare, but not raising the inflation rate.

An extensive literature has discussed the gains from international cooperation in setting fiscal policy. This literature shows that cooperation is desirable if a country's fiscal policy affects world prices and real interest rates. (For details on this result, see the work of Chari and Kehoe (1990) and Canzoneri and Diba (1991).) The kind of desirable cooperation that this literature points to applies equally well to the relationship between, for example, Germany and Canada as it does to that between Germany and Italy; it is not especially related to countries being in a monetary union. Because the issues raised in this literature are well-understood, we abstract from them here. We do so by considering models in which the policies of the cooperating countries taken as a group do not affect world prices and real interest rates. In such models, there can be no gains to cooperation of this sort.

\section{Theory}

We begin with a general setup of a monetary union which makes explicit the logic by which a time inconsistency problem in monetary policy leads to a free-rider problem.

Consider a world economy with $N$ countries indexed $i=1, \ldots, N$ united in a union, with one monetary authority that acts for them all. Each country has a continuum of private agents indexed $j \in[0,1]$, each of whom chooses an action $x_{i j}$. Let $x_{i}=\int x_{i j} d j$

denote the aggregate choice of actions by private agents in country $i$. The government of country $i$ chooses a nonmonetary policy $\tau_{i}$, and the monetary authority of the union chooses 
a common inflation rate for the union denoted $\pi$. The payoffs to private agents are

$$
V\left(\tau_{i}, x_{i j}, x_{i}, \pi\right)
$$

The payoff to the government of country $i$ is the integral of the payoffs to the private agents in that country,

$$
\int V\left(\tau_{i}, x_{i j}, x_{i}, \pi\right) d j
$$

while the payoff to the monetary authority is the sum of the payoffs to the governments:

$$
\sum_{i=1}^{N} \int V\left(\tau_{i}, x_{i j}, x_{i}, \pi\right) d j .
$$

Notice that we have assumed that the policies of individual governments do not directly affect the payoffs to other governments; thus, the only way governments in this economy interact is through the effect of their actions on the common inflation rate. We make this assumption to abstract from standard nonmonetary policy linkages across countries, like tariffs and taxes. These have been analyzed extensively in the literature and have no obvious bearing on issues concerning a monetary union. (See, for example, the work of Chari and Kehoe (1990).)

Typically, a time inconsistency problem in monetary policy arises when the monetary authority cannot effectively commit to an inflation policy. We will show that without effective commitment in a monetary union, there is a free-rider problem, which leads noncooperative outcomes to differ from a benchmark outcome with cooperation. We show that no such problem arises when the monetary authority can commit.

We formalize the lack of commitment that drives the time inconsistency problem with a no commitment game with the following timing. First, the governments choose $\tau_{i}$, then private agents choose $x_{i j}$, and finally the monetary authority chooses $\pi$. We focus on an equilibrium in which all private agents within a country choose the same actions, so that $x_{i j}=x_{i}$ for all $i$ and $j$. 
A noncooperative equilibrium of this game is given by nonmonetary government policies $\bar{\tau}=\left(\tau_{1}, \ldots, \tau_{N}\right)$, private agent decision rules $x_{i}(\bar{\tau})$ that depend on government policies, and a monetary policy function $\pi(\bar{\tau}, \bar{x})$ that depends on government policies $\bar{\tau}$ and the private agents' decisions $\bar{x}=\left(x_{1}, \ldots, x_{N}\right)$ such that $(i)$ for all $\bar{\tau}, \bar{x}$, the policy $\pi(\tau, \bar{x})$ maximizes the monetary authority's payoff; $(i i)$ for each private agent $i j$, for all $\bar{\tau}, x_{i}(\bar{\tau})$ solves

$$
\max _{x_{i j}} V\left(\tau_{i}, x_{i j}, x_{i}(\bar{\tau}), \pi(\bar{\tau}, \bar{x}(\bar{\tau}))\right)
$$

where $\bar{x}(\bar{\tau})=\left(x_{1}(\bar{\tau}), \ldots, x_{N}(\bar{\tau})\right) ;(i i i)$ for each government $i$, given the policies of the other governments $i^{\prime}$, the private agents' decision rules $x_{i}$, and the monetary authority's policy rule $\pi$, the policy $\tau_{i}$ maximizes the payoff to government $i$.

A cooperative equilibrium of this game is defined similarly, with (iii) replaced by this: $\left(i i i^{\prime}\right)$ given the private agents' decision rules $x_{i}$ and the monetary authority's policy rule $\pi$, the vector $\bar{\tau}$ maximizes the sum of the payoffs to the governments. (Notice that clauses $(i)$, (iii), and $\left(i i i^{\prime}\right)$ require that the relevant policies be best responses, while clause (ii) has a fixed-point problem built into it.)

Throughout, we focus on symmetric equilibria, where in addition to all private agents with a country choosing the same decision, all governments choose the same policy. We characterize the equilibria by working backwards. Given government policies $\bar{\tau}$ and private decisions $\bar{x}$, the monetary authority chooses $\pi$ to maximize (3). The resulting monetary policy function $\pi(\bar{\tau}, \bar{x})$ satisfies the first-order condition

$$
\sum_{i=1}^{N} V_{4}\left(\tau_{i}, x_{i}, x_{i}, \pi\right)=0
$$

which in a symmetric equilibrium is simply $V_{4}=0$. (Here $V_{4}$ denotes the derivative of $V$ with respect to its fourth argument. We use similar notation throughout.)

Each private agent maximizes (1), taking as given the government policies $\bar{\tau}$, other private agents' decisions $\bar{x}$, and the monetary policy function $\pi(\bar{\tau}, \bar{x})$. The resulting best response function $X_{i}\left(\tau_{i}, x_{i}, \pi(\bar{\tau}, \bar{x})\right)$ satisfies the first-order condition

$$
V_{2}\left(\tau_{i}, x_{i j}, x_{i}, \pi\right)=0
$$


Let $\bar{x}(\bar{\tau})=\left(x_{1}(\bar{\tau}), \ldots, x_{N}(\bar{\tau})\right)$ denote the fixed point of the best response function, that is,

$$
x_{i}(\bar{\tau})=X_{i}\left(\tau_{i}, x_{i}(\bar{\tau}), \pi(\bar{\tau}, \bar{x}(\bar{\tau}))\right) \text { for all } i \text {. }
$$

In a noncooperative equilibrium, the government of country $i$ maximizes $V\left(\tau_{i}, x_{i}(\bar{\tau})\right.$, $\left.x_{i}(\bar{\tau}), \pi(\bar{\tau})\right)$ where $\Pi(\bar{\tau})=\pi(\bar{\tau}, \bar{x}(\bar{\tau}))$ denotes the monetary policy function $\pi(\bar{\tau}, \bar{x})$ evaluated at the private decision rules $\bar{x}(\bar{\tau})$. Then the government's first-order condition is

$$
V_{1}+\left(V_{2}+V_{3}\right) \frac{\partial x_{i}}{\partial \tau_{i}}+V_{4} \frac{\partial \Pi}{\partial \tau_{i}}=0
$$

where $\partial \Pi / \partial \tau_{i}=\partial \pi / \partial \tau_{i}+\sum_{j=1}^{N}\left(\partial \pi / \partial x_{j}\right)\left(\partial x_{j} / \partial \tau_{i}\right)$. Notice that $\partial \Pi / \partial \tau_{i}$ captures both the direct effect of changes in government policy $\tau_{i}$ on inflation and the indirect effects through changes in private agents' decisions.

In a cooperative equilibrium, the governments jointly choose $\tau$ to maximize

$$
\sum_{i=1}^{N} V\left(\tau_{i}, x_{i}(\bar{\tau}), x_{i}(\bar{\tau}), \Pi(\bar{\tau})\right)
$$

Taking the first-order conditions and then imposing symmetry gives

$$
V_{1}+\left(V_{2}+V_{3}\right)\left[\frac{\partial x_{i}}{\partial \tau_{i}}+\sum_{j \neq i} \frac{\partial x_{j}}{\partial \tau_{i}}\right]+N V_{4} \frac{\partial \Pi}{\partial \tau_{i}}=0 .
$$

We can use these conditions to show the following.

Proposition 1. (Free-riding without commitment) Suppose there is a unique cooperative equilibrium with $V_{3} \neq 0$ and $\partial x_{j} / \partial \tau_{i} \neq 0$. Then the noncooperative and cooperative policies without commitment differ, and the cooperative equilibrium has strictly higher welfare than the noncooperative equilibrium. If either $V_{3}=0$ or $\partial x_{j} / \partial \tau_{i}=0$ in the cooperative equilibrium, then the two equilibria coincide.

Proof. Substituting the first-order conditions for the monetary authority and the private agents into (8), we have that in a noncooperative equilibrium,

$$
V_{1}+V_{3} \frac{\partial x_{i}}{\partial \tau_{i}}=0
$$


Using similar substitutions, we have that in a cooperative equilibrium,

(11) $V_{1}+V_{3}\left[\frac{\partial x_{i}}{\partial \tau_{i}}+\sum_{j \neq i} \frac{\partial x_{j}}{\partial \tau_{i}}\right]=0$.

Comparing (10) and (11), we see that the policies in the two equilibria are different if and only if both $V_{3} \neq 0$ and $\partial x_{j} / \partial \tau_{i} \neq 0$ in the cooperative equilibrium. Since it is feasible for the governments in a cooperative equilibrium to choose the noncooperative policies, it follows from the uniqueness of the cooperative equilibrium that welfare is strictly higher in the cooperative equilibrium whenever the two equilibria differ. Q.E.D.

From (7) it is easy to see that

$$
\frac{\partial x_{j}}{\partial \tau_{i}}=X_{j \pi} \frac{\partial \Pi / \partial \tau_{j}}{1-X_{j x}}
$$

where $X_{j x}$ is the derivative of the fixed point map in (7) with respect to $x_{j}$. Notice that if private agents' decisions do not depend on their predictions of inflation so that $X_{j \pi}=0$ or the inflation rate does not depend on the government policies so that $\partial \Pi / \partial \tau_{j}=0$ then $\partial x_{j} / \partial \tau_{i}=0$ and there is no free rider problem.

At a superficial level, the free-rider problem seems to arise solely because inflation confers a common cost on the members of the union while an individual government cares only about the effect of inflation on its own payoffs. The source of the free-rider problem is, however, subtler. For example, suppose that $V_{3}=0$ - say, because private agents take no actions. Then the equilibria in the two regimes coincide even though individual governments care only about the effects of inflation on their own countries. In this example with $V_{3}=0$, the two equilibria coincide because of an envelope argument. In the cooperative equilibrium, the monetary authority chooses inflation to balance the costs and benefits, so that at the margin, an incremental change in inflation has no effect on welfare. Starting at this outcome, a noncooperative government realizes that at the margin the induced effect of its policies on welfare through their effect on inflation is zero. In both the cooperative and noncooperative 
equilibria, therefore, a government's policies at the margin affect only that government's welfare. Hence, there is no free-rider problem.

When $V_{3} \neq 0$ and $\partial x_{j} / \partial \tau_{i} \neq 0$, however, there is a free-rider problem. Starting at the cooperative outcome, if country $i$ changes its policies, then the monetary authority responds by changing the inflation rate. At the margin, if we neglect the induced effects on private decisions $x$, this change has no effect on welfare. The key is, however, that the induced change in the inflation rate also induces changes in private decisions $x$. It is through this channel that the free-rider problem occurs. A change in the government policy $\tau_{i}$ makes the private agents in all the countries predict a change in inflation, and this predicted change makes them change their actions. (Mechanically we can see this from equation (12) which gives the change in private agent decisions in country $j$ due to changes in government policy in country $i$. For this change to be nonzero we need $\partial \Pi / \partial \tau_{i} \neq 0$ and $X_{j \pi} \neq 0$.) When $V_{3} \neq 0$ this change in private decisions implies that a change in government policy in country $i$ induces a change in welfare in country $j$ and thus leads to a free rider problem. Later we will illustrate the detailed economic channels of the free-rider problem in our applications of this theory to three specific types of nonmonetary policies.

We now show that if there are no time inconsistency problems, then there are no freerider problems. There are no time inconsistency problems when there is some commitment or reputational mechanism. For simplicity, here we simply assume that the monetary authority can commit to its policies. A similar analysis would apply to the reputational equilibria that support commitment in the repeated game version of the model.

The timing in the commitment game is as follows. First the monetary authority chooses $\pi$, then governments choose $\tau_{i}$, and finally private agents choose $x_{i j}$.

A noncooperative equilibrium of this game is given by a monetary policy $\pi$, government policy functions $\tau_{i}(\pi)$, and private agent decision rules $x_{i}(\pi, \bar{\tau})$ such that $(i)$ for each private 
agent $i j$, for all $\pi$ and $\bar{\tau}, x_{i}(\pi, \bar{\tau})$ solves

$$
\max _{x_{i j}} V\left(\tau_{i}, x_{i j}, x_{i}(\pi, \bar{\tau}), \pi\right)
$$

(ii) for each government $i$, for all $\pi$, given the policies of the other governments $\tau_{i^{\prime}}(\pi)$ and the private agent decision rules $x_{i}(\pi, \bar{\tau})$, the policy $\tau_{i}(\pi)$ maximizes the payoff to government $i$; and (iii) given the government policy functions $\tau_{i}$ and the private agent decision rules $x_{i}$, the policy $\pi$ maximizes the monetary authority's payoff.

A cooperative equilibrium of the commitment game is defined similarly, but with ( $i i)$ replaced by this: $\left(i i^{\prime}\right)$ for all $\pi$, given the private agent decision rules $x_{i}(\pi, \bar{\tau})$, the policy $\tau_{i}(\pi)$ maximizes the sum of the payoffs to the governments.

We then have

Proposition 2. (No free-riding with commitment) With commitment, the noncooperative and the cooperative policies coincide and the welfare in the resulting equilibria is the same.

Proof. Consider private agent optimality. From (13) it follows that the first-order condition for private agents in both equilibria is $V_{2}=0$ and that $x_{i}(\pi, \bar{\tau})$ depends only on $\pi$ and $\tau_{i}$ for all $i$, so that for $j \neq i$,

$$
\frac{\partial x_{i}}{\partial \tau_{j}}=0 .
$$

In the noncooperative equilibrium, the governments choose $\tau_{i}$ to maximize

$$
V\left(\tau_{i}, x_{i}(\pi, \bar{\tau}), x_{i}(\pi, \bar{\tau}), \pi\right)
$$

Using $V_{2}=0$, we can write the first-order condition in a noncooperative equilibrium as

$$
V_{1}+V_{3} \frac{\partial x_{i}}{\partial \tau_{i}}=0
$$

Acting cooperatively, the governments choose $\tau_{i}$ to maximize

$$
\sum_{i=1}^{N} V\left(\tau_{i}, x_{i}(\pi, \bar{\tau}), x_{i}(\pi, \bar{\tau}), \pi\right) .
$$


Using $V_{2}=0$ and (14), we see that the first-order condition for this problem reduces to (15). Clearly, the noncooperative and cooperative solutions coincide. Thus, with commitment, there is no free-rider problem. Q.E.D.

The intuition for the differing results in the environments with and without commitment is as follows. In both environments, a government in a given country $i$ does not care directly about the government policies or the private agent choices in any other country $j$. Without commitment, government policies in other countries induce changes in the common inflation rate, and thus induce changes in private agent choices in country $i$. This linkage leads policies in country $i$ to depend on government policy choices in country $j$. This subtle linkage leads to a free-rider problem. With commitment, the links among governments in different countries are broken, and there is no free-rider problem.

In some of our applications, some of the private agents are not residents of any of the countries. For example, in our application to fiscal policy, there are lenders who do not reside in any of the countries. Propositions 1 and 2 generalize to such situations.

Consider a variant of the environment described here in which the behavior of private agent $i j$ is summarized by a best response function $X_{i}\left(\tau_{i}, \pi, x_{i}\right)$, where $x_{i}=\int x_{i j} d j$. In the noncommitment game, the private agent decision rules are summarized by a fixed point of the best response function, namely, a function $x_{i}(\bar{\tau})$ that solves

$$
x_{i}(\bar{\tau})=X_{i}\left(\tau_{i}, \pi(\bar{\tau}, \bar{x}(\bar{\tau})), x_{i}(\bar{\tau})\right)
$$

Here an analog of Proposition 1 holds with one slight modification. The conditions under which the noncooperative and cooperative policies without commitment differ are

$$
V_{2}+V_{3} \neq 0 \text { and } \partial x_{j} / \partial \tau_{j} \neq 0
$$

Proposition 2 holds as stated.

In our application to bank regulation, the monetary authority has essentially a zeroone decision on whether to bail out the banks. This feature implies that, even though the 
monetary authority is maximizing, it does not set $V_{4}$ equal to zero. Inspecting (8) and (9), we see that if $V_{4} \partial \Pi / \partial \tau_{i}$ is not equal to zero, then an analog of Proposition 1 typically applies. Proposition 2 holds as stated.

\section{Applications}

Now we apply this general theory to some particular examples of nonmonetary policies which can lead to free-riding in monetary unions when monetary authorities cannot commit to their policies.

\subsection{Labor Market Policy}

First we apply our theory to a type of nonmonetary policy that governments of members of a monetary union control: labor market policy. For this application, we use the classic model of time inconsistency in monetary policy due to Kydland and Prescott (1977) and Barro and Gordon (1983), in which ex post inflation reduces unemployment. We modify this model to allow governments to set labor market policies which determine the natural rate of unemployment. We show that the free-rider problem leads governments to adopt policies that result in higher unemployment and inflation than would occur in an efficient allocation.

Consider the following modified version of Kydland and Prescott's and Barro and Gordon's model. In this example, the natural rate of unemployment in country $i, \bar{u}\left(\tau_{i}\right)$, is affected by labor market policies in that country, denoted by $\tau_{i}$. For simplicity, let $\bar{u}\left(\tau_{i}\right)=$ $\bar{u}-\tau_{i}$. The realized unemployment rate $u_{i}$ is determined by the natural unemployment rate

and the $\log$ of the real wage $x_{i}-\pi$, which is the difference between the log of the nominal wage and the $\log$ of the price level. Since initial prices are given, $\pi$ is both the price level and the inflation rate. Specifically,

$$
u_{i}=x_{i}-\pi+\bar{u}\left(\tau_{i}\right)
$$

Each private agent chooses a wage $x_{i j}$, and the wage in country $i$ is given by $x_{i}=\int x_{i j} d j$. 
The objective function of each private agent $i j$ is

$$
-\frac{1}{2}\left(x_{i j}-\pi\right)^{2}-\frac{a}{2} u_{i}^{2}-\frac{b}{2} \pi^{2}-\frac{c}{2} \tau_{i}^{2}
$$

where $a, b$, and $c$ are constants. The first term in this objective function provides a target real wage for the private agents, the second and the third terms reflect concerns over aggregate unemployment and inflation, and the last term captures the cost of altering labor market policies which affect the natural rate of unemployment. Substituting for $u_{i}$ from (17) and $\bar{u}\left(\tau_{i}\right)=\bar{u}-\tau_{i}$ gives private agents these payoffs:

$$
V\left(\tau_{i}, x_{i j}, x_{i}, \pi\right)=-\frac{1}{2}\left(x_{i j}-\pi\right)^{2}-\frac{a}{2}\left(x_{i}-\pi+\bar{u}-\tau_{i}\right)^{2}-\frac{b}{2} \pi^{2}-\frac{c}{2} \tau_{i}^{2} .
$$

The payoff to government $i$ is $\int V\left(\tau_{i}, x_{i j}, x_{i}, \pi\right) d i$, and the payoff to the monetary authority is the sum of the governments' payoffs. These payoff functions ensure that private agents choose their wages to be the expected value of inflation and that the monetary authority cares about the average rate of unemployment. (To see why this assumption matters, see the work of Chari et al. (1989).) In much of the literature, the payoffs to the private agents are given (implicitly) by the first term on the right side of (19) and the payoffs to the monetary authority are given by the second and third terms. We choose to combine these terms so that the governments and the monetary authority are benevolent.

Equilibria of the no commitment and commitment games in this world are defined exactly as in the theory section above. To show that there is a free-rider problem in the no commitment game, we need show only that $V_{3} \neq 0$ and $\partial x_{i}(\bar{\tau}) / \partial \tau_{j} \neq 0$ in the cooperative equilibrium. To do so, we first use the monetary authority's first-order condition to derive

$$
\pi(\bar{\tau}, \bar{x})=\frac{(1+a) \sum x_{i}+N a \bar{u}-a \sum \tau_{i}}{N(1+a+b)} .
$$

Next we note that the private agent's first-order condition yields $x_{i}=\pi$. Clearly, $x_{i}$ is the same for all $i$, and we denote it by $x$. Then $x(\bar{\tau})$ solves the fixed-point problem $x(\bar{\tau})=$ $\pi(\bar{\tau}, \bar{x}(\bar{\tau}))$, where $\bar{x}(\bar{\tau})=(x(\bar{\tau}), \ldots, x(\bar{\tau}))$. Using $(20)$, we have that

$$
x(\bar{\tau})=\frac{a}{b}\left(\bar{u}-\frac{\sum \tau_{i}}{N}\right) .
$$


Clearly, $\partial x_{i}(\bar{\tau}) / \partial \tau_{j}=-a / b N \neq 0$ as long as $a$ is nonzero. To calculate the value of $V_{3}$, we need to solve for the cooperative equilibrium policies. It is straightforward to use the monetary authority's first-order condition to show that the cooperative equilibrium policies are given by $\tau^{C}=\left[a+\left(a^{2} / b\right) \bar{u}\right] /\left[a+\left(a^{2} / b\right)+c\right]$. Using (20) and (21), we obtain

$$
V_{3}=\frac{a c \bar{u}}{a+\left(a^{2} / b\right)+c}
$$

If $a c \bar{u} \neq 0$, we have that $V_{3} \neq 0$. From Proposition 1, the following proposition is immediate:

Proposition 3. (Free-riding in labor market policies without commitment) In the game with no commitment, the noncooperative and cooperative equilibria differ if ac $\bar{u}$ is nonzero and the cooperative equilibrium has strictly higher welfare than the noncooperative equilibrium. If $a c \bar{u}=0$, the two equilibria coincide.

If $a c \bar{u}=0$, then there is no time inconsistency problem in monetary policy. This condition is related to similar conditions in the literature following Kydland and Prescott (1977) and Barro and Gordon (1983). In that literature, $\bar{u}$ is a constant, and there is only one country. A standard result in that literature is that there is no time inconsistency problem if $a=0$ or if $\bar{u}=0$, that is, if the monetary authority does not have an incentive to reduce unemployment below the natural rate. In our model in which the natural rate can be affected by labor market policies, if $c=0$, then each government would simply set its policies so that the natural rate is zero and there would be no time inconsistency problem in monetary policy. Thus, Proposition 3 essentially says that whenever there is a time inconsistency problem in monetary policy, there is a free-rider problem in labor market policy.

It is easy to show that the equilibrium inflation rate under noncooperation is

$$
\pi^{N}=\frac{a c \bar{u} / b}{a+\left(a^{2} / b N\right)+c}
$$

and the equilibrium inflation rate under cooperation is

$$
\pi^{C}=\frac{a c \bar{u} / b}{a+\left(a^{2} / b\right)+c} .
$$


Clearly, the noncooperative level of inflation $\pi^{N}$ is greater than the corresponding cooperative level $\pi^{C}$. Notice that the noncooperative inflation rate rises monotonically with the number of countries $N$. In this sense, the free-rider problem gets worse as the number of countries gets larger.

The free-rider problem can be eliminated by imposing constraints on the labor market policies of member governments. The following corollary is immediate.

Corollary. (Labor market policy constraints and the free-rider problem) In the game without commitment, if each government is required to set its labor market policy $\tau_{i} \geq \tau^{C}$, then the noncooperative equilibrium attains the cooperative benchmark.

Clearly, Proposition 2 applies to this environment, and thus with commitment, there is no free-rider problem. Under commitment, the cooperative level of inflation is zero.

Notice that the constraints on labor market policy that eliminate the free-rider problem in labor market policy also help mitigate the time inconsistency problem in monetary policy because they lower inflation from $\pi^{N}$ to $\pi^{C}$. They do not, however, eliminate the time inconsistency problem since $\pi^{C}$ is still positive and thus $\pi^{C}$ is higher than the cooperative level of inflation with commitment, namely zero.

\subsection{Fiscal Policy}

Now we apply our theory to a second type of nonmonetary policy: fiscal policy. Each of the many governments in a monetary union issues nominal debt to smooth consumption. The monetary authority chooses a common inflation rate. This inflation reduces the real return on debt and effectively serves as a kind of partial default. We show that when the monetary authority cannot effectively commit to its monetary policy, there is a free-rider problem: governments issue too much debt, inflation is too high, and output is too low relative to a cooperative benchmark. This free-rider problem can be solved by imposing constraints on the amount of debt that governments can issue. Such constraints lead to the 
benchmark levels of inflation and output.

Consider a two-period model with $N$ identical countries indexed $i=1, \ldots, N$ that are small in the world economy. The countries are united in a monetary union. In period 0, the countries start with an identical price level $p_{0}$, which is given. Each country issues nominal debt in period 0 to lenders who live outside of these countries. These foreign lenders are risk neutral and have a discount factor of $\beta$. In period 1 , the monetary authority determines the unionwide monetary policy. We model monetary policy as the choice of the price level in period $1, p_{1}$. In each country, in period 0 , output is a constant given by $\omega$, while in period 1 , output $y(\pi)$ is a decreasing and concave function of the common inflation rate from period 0 to period 1 , denoted by $\pi=p_{1} / p_{0}$. We assume that $y(\pi)$ satisfies the Inada conditions that $y_{\pi}(0)=0$ and $y_{\pi}(\infty)=-\infty$.

We now set up the individual country government budget constraints and objective functions. The budget constraints of the government in country $i$ are

$$
\begin{aligned}
& p_{0} c_{i 0}=\omega+q b_{i} \\
& p_{1} c_{i 1}=p_{1} y-b_{i}
\end{aligned}
$$

where $b_{i}$ is nominal debt sold to foreign lenders at price $q$ and $c_{i 0}$ and $c_{i 1}$ denote consumption of the residents of country $i$ in the two periods. The objective function of the country $i$ government is

$$
U\left(c_{i 0}\right)+\beta U\left(c_{i 1}\right)
$$

The model starts with $p_{0}$ given, so setting $p_{0}=1$ is convenient. A government's period 1 budget constraint is, then,

$$
c_{i 1}=y(\pi)-b_{i} / \pi
$$

We will assume that period 0 output, $\omega$, is sufficiently smaller than $y(0)$, so that the governments have an incentive to borrow. The monetary authority's objective function is the sum of the objective functions of the governments. 
The timing of the model in period 0 is that first the governments choose their debt levels to foreign lenders $b_{i}$, and then the price $q$ of that debt is determined. In period 1 , the monetary authority chooses the common inflation rate $\pi$. We consider two equilibria: a noncooperative equilibrium in which the governments simultaneously choose their debt levels to maximize their own objective functions and a cooperative equilibrium in which the debt levels are chosen to maximize the sum of the objective functions. This timing reflects the idea that the monetary authority cannot commit to the policies it will follow. Specifically, the monetary authority takes the debt levels $\bar{b}=\left(b_{1}, \ldots, b_{N}\right)$ as given and then chooses the inflation rate optimally. When choosing their debt levels, the governments recognize that their choices affect future inflation by influencing the actions of the monetary authority.

In both equilibria, we solve the model by starting at the end. In both regimes, the problems of the monetary authority and the lenders are the same. Taking the debt levels as given, the monetary authority chooses $\pi$ to solve

$$
\max _{\pi} \sum_{i} U\left(y(\pi)-b_{i} / \pi\right)
$$

Let $\pi(\bar{b})$ denote the resulting monetary policy function. Consider next the foreign lenders. Since they are risk neutral, behave competitively, and have discount factor $\beta$, the debt price function is given by

$$
q(\bar{b})=\beta / \pi(\bar{b})
$$

In the noncooperative equilibrium, the government of country $i$, taking other countries' debt levels as given, solves

$$
\max _{b_{i}} U\left(\omega+q(\bar{b}) b_{i}\right)+\beta U\left(y(\pi(\bar{b}))-b_{i} / \pi(\bar{b})\right) .
$$

In the cooperative equilibrium, the vector of debt levels $\bar{b}$ is chosen to solve

$$
\max _{\bar{b}} \sum_{i}\left[U\left(\omega+q(\bar{b}) b_{i}\right)+\beta U\left(y(\pi(\bar{b}))-b_{i} / \pi(\bar{b})\right)\right]
$$


A noncooperative equilibrium is given by a vector of debt levels $\bar{b}$ that solves (27), a debt price function $q$ that solves (26), and a monetary policy function $\pi$ that solves (25). A cooperative equilibrium is defined similarly except that the vector of debt levels $\bar{b}$ solves (28).

This fiscal policy environment is a special case of the general setup that we discussed at the end of the theory section. To see this, let $\tau_{i}=b_{i}$ and $x_{i}=q$. Then the payoff to government $i$ is given by the integral over $j$ of

$$
V\left(\tau_{i}, x_{i j}, x_{i}, \pi\right)=U\left(\omega+x_{i} \tau_{i}\right)+\beta U\left(y(\pi)-\tau_{i} / \pi\right) .
$$

Notice that the payoff does not depend on the action $x_{i j}$ of an individual private agent. The monetary policy function in this case $\pi(\bar{\tau})$ does not depend on private decisions $\bar{x}$. The private decision rule is given by $x_{i}(\bar{\tau})=\beta / \pi(\bar{\tau})$. The modified conditions (16) hold here. Clearly, $V_{2}+V_{3}=U^{\prime}\left(c_{i 0}\right) \tau_{i} \neq 0$. It is easy to show that

$$
\frac{\partial x_{i}}{\partial \tau_{j}}=-\frac{\beta}{\pi^{2}} \frac{\partial \pi}{\partial \tau_{j}}
$$

is nonzero at the cooperative benchmark. We then have the following proposition.

Proposition 4. (Free-riding in fiscal policies, without commitment) In the game with no commitment, the noncooperative and cooperative equilibria differ and the cooperative equilibrium has strictly higher welfare than the noncooperative equilibrium.

The natural presumption is that debt and inflation are higher in the noncooperative equilibrium. It is possible to show that this presumption holds when $y=\bar{y}-\pi^{\alpha} / \sigma$ with $\sigma>1$. For this example, we can show that when there is no commitment, if the countries in the noncooperative regime are constrained to keep their debt at or below the cooperative levels, then they will achieve the cooperative outcome. Note that the cooperative outcome without commitment has positive inflation. (This follows since at zero inflation $y_{\pi}(0)=0$ so that at the margin there is a gain from inflating away some nominal debt with an increase in inflation.) When there is commitment, the cooperative outcome has zero inflation. Since 
the cooperative equilibrium without commitment has positive but lower inflation than the noncooperative equilibrium without commitment, constraints on fiscal policy mitigate but do not eliminate the time inconsistency problem in monetary policy.

Applying Proposition 2 to this environment, we know that once a monetary policy has been committed to, binding constraints on future debt issues can only reduce welfare.

Propositions 2 and 4 imply that a time inconsistency problem in monetary policy is at the heart of a free-rider problem in fiscal policy. They also imply that the question of whether debt constraints are desirable is intimately connected to the extent to which the monetary authority can commit to monetary policy. From Proposition 4 and the above discussion, we know that as long as such commitment is not possible, appropriately chosen debt constraints improve welfare while if such commitment is possible, debt constraints can only reduce welfare.

The economy with commitment is broadly similar to the economies studied in an extensive literature that has discussed the gains from international cooperation in setting fiscal policy. (See, for example, the work of Chari and Kehoe (1990) and Canzoneri and Diba (1991).) As noted in the introduction, this literature shows that cooperation is desirable if a country's fiscal policy affects world prices and real interest rates. In our model, there are no gains to cooperation under commitment because we have assumed that the monetary union is small in the world in the sense that the world interest rate is independent of the fiscal policy decisions of the union's members.

Suppose, instead, we had considered a general equilibrium model with no outside lenders, so that countries in the union constitute the entire world. Specifically, suppose that each country chooses its spending level on a public good that benefits its own residents and finances the spending with debt and distorting taxes. In such a formulation, even with commitment by the monetary authority, the noncooperative and cooperative equilibria do not coincide. This is because any country's spending decision affects the world interest rate 
and, hence, other countries' welfare. Since these types of gains to cooperation are not related to the formation of a monetary union, we have chosen to abstract from them.

\subsection{Bank Regulation}

Now we apply our theory to a third type of nonmonetary policy: bank regulation. Here the time inconsistency problem arises because the monetary authority cannot commit to not bailing out insolvent banks. Government policy consists of determining the level of regulation of banks. The free-rider problem leads to lax regulation of banks, frequent bank bailouts, and a high rate of inflation. The general argument in Propositions 1 and 2, that time inconsistency problems lead to free-rider problems, applies here, with the modifications discussed at the end of the theory section.

We assume that depositors in banks are fully insured, banks have limited liability, and the monetary authority bails out the depositors in insolvent banks. Deposit insurance together with limited liability creates an incentive for banks to take on excessive risk. We assume that governments regulate banks to limit risk-taking. In this application, the freerider problem leads governments to do too little regulation and banks to take on too much risk compared to what they would do in the efficient allocation.

The environment is as follows. The monetary union consists of $N$ countries indexed $i=1, \ldots, N$. The aggregate state of the world economy is $s \in\{H, L\}$, where $H$ denotes a boom (or a high state) and $L$ denotes a recession (or a low state). The probabilities of $H$ and $L$ are $\mu_{H}$ and $\mu_{L}$, respectively. Output is produced as follows. There are a large number of projects in each country $i$, indexed by $z_{i} \in[0,1 / 2]$. A project of type $z$ yields a return $R$ per unit of investment when it succeeds and 0 otherwise. The probability of success in a boom is $p_{H}(z)=(1 / 2)+z$, and the probability of success in a recession is $p_{L}(z)=(1 / 2)-z$. We will show that in each country $i$ only one type of project-say, $z_{i}$-will be chosen. Since each country has a large number of projects, total output in country $i$ in state $s \in\{H, L\}$ is $p_{s}\left(z_{i}\right) R$. Notice that when projects with a higher value of $z$ are chosen, the distribution of 
output is a mean-preserving spread of the output when projects with a lower value of $z$ are chosen.

This monetary union has many banks. Each bank can finance up to one unit of investment. A bank in country $i$ obtains funds from depositors who are paid an interest rate $r_{i}$. Banks have limited liability in that they must pay depositors only if bank receipts exceed bank obligations. If bank receipts fall short of obligations, then banks pay zero, and the monetary authority pays off the depositors by liquidating the bank's assets and by printing money to cover any shortfall. The government of country $i=1, \ldots, N$ can do some costly supervision at a level of $\tau_{i}$ and prohibit banks from financing projects with $z>\tau_{i}$. This supervision of bank activities is what will represent bank regulation in this world.

We now describe optimal behavior by banks for a given inflation rate $\pi$ and given supervision levels $\bar{\tau}=\left(\tau_{1}, \ldots, \tau_{N}\right)$. A bank's maximization problem is to choose which type of project to fund. A bank in country $i$, taking the interest rate $r_{i}$ on its deposits and the supervision level $\tau_{i}$ as given, chooses $z$ to maximize profits:

$$
q_{H i} \max \left\{p_{H}(z) R-r_{i}, 0\right\}+q_{L i} \max \left\{p_{L}(z) R-r_{i}, 0\right\}
$$

subject to $z \leq \tau_{i}$. Here $q_{H i}$ and $q_{L i}$ are the prices in country $i$ for one unit of consumption in state $H$ and $L$, respectively.

For some given policies $\pi, \bar{\tau}$, and state prices $q_{s i}$, for $i=1, \ldots, N, s=H, L$, a competitive banking equilibrium consists of portfolio rules $z_{i}\left(\tau_{i}\right)$ and deposit rates $r_{i}\left(\tau_{i}\right)$ such that (i) $z_{i}\left(\tau_{i}\right)$ solves $(30)$ given $r_{i}\left(\tau_{i}\right)$ and $(i i)$ profits in (30) are zero. Then we have this:

Lemma. In a competitive banking equilibrium, $z_{i}\left(\tau_{i}\right)=\tau_{i}$ and $r_{i}=p_{H}\left(z_{i}\left(\tau_{i}\right)\right) R$.

Proof. Since profits are zero in equilibrium, each term in (30) is zero. We drop the $i$ subscript for simplicity. Since $p_{H}(z) \geq p_{L}(z), r=p_{H}(z) R$ and $p_{L}(z) R-r \leq 0$. To see that $z=\tau$, suppose, by way of contradiction, that in equilibrium $z<\tau$. Then increasing $z$ increases $p_{H}(z) R-r$ and, thus, increases the first term in (30). The second term is unchanged 
since $p_{L}(z) R-r$ falls from a value of at most zero. Thus, increasing $z$ increases profits, which contradicts profit maximization. Q.E.D.

We assume that the objective function for the consumers and the government of country $i$ is

$$
\sum_{s} \mu_{s} U\left(y_{s i}, \pi_{s}\right)
$$

where $y_{s i}$ denotes output in country $i$ and $\pi_{s}$ denotes the common inflation rate across countries in state $s$. We assume that consumers cannot share risk across countries, so that each consumer simply consumes the output of country $i$. We also assume that the utility function is increasing in output and decreasing in the inflation rate. Output in each country $i$ is given by the returns from the banks' projects less the costs of supervising banks, $e\left(\tau_{i}\right)$, which is increasing in $\tau_{i}$. Using the lemma, we know that all banks in a given country choose projects of the same type $z_{i}$, so that total output in country $i$ is given by $y_{s}\left(z_{i}, \tau_{i}\right)=$ $p_{s}\left(z_{i}\right) R-e\left(\tau_{i}\right)$.

The monetary authority is required to print money to bail out any bank which cannot pay off its depositors, namely, when $r_{i}<p_{s}\left(z_{i}\right) R$. An inflation rate of $\pi$ raises revenues of $\pi M$, where $M$ is the initial money stock that we normalize to 1 . Thus, the monetary authority must set $\pi$ so that

$$
\pi_{s}(\bar{r}, \bar{z})=\sum_{i} \max \left\{r_{i}-p_{s}\left(z_{i}\right) R, 0\right\}
$$

where $\bar{r}=\left(r_{1}, \ldots, r_{N}\right)$ and $\bar{z}=\left(z_{1}, \ldots, z_{N}\right)$.

A noncooperative equilibrium is given by a vector of bank supervision levels $\bar{\tau}$ that solve

$$
\max \sum_{s} \mu_{s} U\left(y_{s}\left(z_{i}(\bar{\tau}), \tau_{i}\right), \pi_{s}(\bar{r}(\bar{\tau}), \bar{z}(\bar{\tau}))\right)
$$

along with a competitive banking equilibrium $(\bar{r}(\bar{\tau}), \bar{z}(\bar{\tau}))$ and a monetary policy function $\pi$ that solves (32). A cooperative equilibrium is defined similarly except that the vector of supervision levels $\bar{\tau}$ maximizes the sum of objective functions across countries. 
The logic of the general setup discussed at the end of the theory section can be applied to this bank regulation environment. To see how, let $x_{i}$ be the vector $\left(x_{i r}, x_{i z}\right)=\left(r_{i}, z_{i}\right)$ and $\pi$ be the vector $\left(\pi_{L}, \pi_{H}\right)$. To keep the notation simple, we let the monetary authority either bail out all insolvent banks by setting $\pi_{s}=\pi_{s}(\bar{r}, \bar{z})$ or not bail out any insolvent bank by setting $\pi_{s}=0$. We let the indicator variable $d=1$ if there is a bailout and $d=0$ if not. Since banks within each country are identical, we need only consider a representative bank for each country. Hence, there is no $x_{i j}$ in payoffs. Then the payoff to government $i$ is given by

$$
\left.V\left(\tau_{i}, x_{i}, \pi\right)=\sum_{s} \mu_{s} U\left(y_{s}\left(z_{i}, \tau_{i}\right), \pi_{s}\right)\right) \text { if either } r_{i} \leq p_{s}\left(z_{i}\right) R \text { or } d=1
$$

and otherwise equals an arbitrarily large negative number, say $-K$. This payoff has the feature that the payoff to the government coincides with the payoff in (31) if either the banks in that country are solvent or there is a bailout. The payoff to the monetary authority is then $\sum_{i} V\left(\tau_{i}, x_{i}, \pi\right)$. Since the cost of not bailing out insolvent banks is arbitrarily large, the monetary authority finds bailing out all insolvent banks optimal.

Consider applying the extension of Proposition 1. Government $i$ 's first-order condition under noncooperation for $\tau_{i}$ is

$$
V_{\tau}+\frac{\partial V}{\partial r_{i}} \frac{\partial r_{i}}{\partial \tau_{i}}+\frac{\partial V}{\partial z_{i}} \frac{\partial z_{i}}{\partial \tau_{i}}+V_{\pi} \frac{\partial \Pi}{\partial \tau_{i}}=0 .
$$

This is the analog of (8). The first-order condition for $r_{i}$ under cooperation is

$$
V_{\tau}+\frac{\partial V}{\partial r_{i}} \frac{\partial r_{i}}{\partial \tau_{i}}+\frac{\partial V}{\partial z_{i}} \frac{\partial z_{i}}{\partial \tau_{i}}+N V_{\pi} \frac{\partial \Pi}{\partial \tau_{i}}=0
$$

This is the analog of (9) and uses the feature that here neither $r_{i}$ nor $z_{i}$ varies with $\tau_{j}$. Since $V_{\pi} \neq 0$ and $\partial \Pi / \partial \tau_{i} \neq 0$, policies under cooperation and noncooperation differ. We have proven the following proposition:

Proposition 5. (Free-riding in bank regulation without commitment) The noncooperation and cooperation policies without commitment differ and the cooperative equilibrium has strictly higher welfare than the noncooperative equilibrium. 
The mechanism that leads to the free-rider problem here is as follows. When bank supervision by a government slackens, its banks take on riskier portfolios, and in a recession, the monetary authority must make larger bailouts. These larger bailouts lead to higher inflation and lower welfare. In a noncooperative equilibrium, each government trades off the gains from slacker supervision against the cost it bears from higher inflation. In particular, each government ignores the costs on others of the higher inflation that its actions induce. In a cooperative equilibrium, the gains from slacker supervision are traded off against the costs that all bear from higher inflation. These tradeoffs lead to higher inflation and lower welfare in the noncooperative equilibrium.

One way to mitigate the free-rider problem with regard to this type of nonmonetary policy is to have countries set a mutually agreed upon level of bank supervision. Here that level is the cooperative level. Finally, Proposition 2 holds as stated for this environment, so that when there is commitment by the monetary authority, there is no free-rider problem.

\section{Conclusion}

We have argued that in the context of monetary unions, a time inconsistency problem in monetary policy leads to a novel type of free-rider problem in the setting of member governments' nonmonetary policies. The free-rider problem can be eliminated by setting constraints on the nonmonetary policies. Such constraints not only lead to better nonmonetary policies; they also lead to better monetary policies.

Our analysis also shows that the desirability of constraints on various nonmonetary policies in monetary unions depends critically on the extent of commitment of the union's monetary authority. If that monetary authority can commit to its policies, constraints can only impose costs. If the monetary authority cannot commit, then there is a free-rider problem, and constraints may be desirable. 


\section{References}

Barro, Robert J. and David B. Gordon. 1983. A Positive Theory of Monetary Policy in a Natural Rate Model. Journal of Political Economy 91 (4, August), 589-610.

Beetsma, Roel and Harald Uhlig. 1999. An Analysis of the Stability and Growth Pact. Economic Journal 109 (458, October), 546-71.

Buiter, Willem, Giancarlo Corsetti, and Nouriel Roubini. 1993. Excessive Deficits: Sense and Nonsense in the Treaty of Maastricht. Economic Policy: A European Forum 8 (16, April), 57-100.

Canzoneri, Matthew B. and Behzad T. Diba. 1991. Fiscal Deficits, Financial Integration, and a Central Bank for Europe. Journal of the Japanese and International Economy 5 (4, December), 381-403.

Chari, V. V. and Patrick J. Kehoe. 1990. International Coordination of Fiscal Policy in Limiting Economies. Journal of Political Economy 98 (3, June), 617-36.

Chari, V. V., Patrick J. Kehoe, and Edward C. Prescott. 1989. Time Consistency and Policy. In Modern Business Cycle Theory, ed. Robert J. Barro, pp. 265-305. Cambridge, Mass.: Harvard University Press.

Cooper, Russell W. and Hubert Kempf. 2001a. Dollarization and the Conquest of Hyperinflation in Divided Societies. Federal Reserve Bank of Minneapolis Quarterly Review 25 (3, Summer), 3-12.

. 2001b. On Dollarization. Manuscript, Boston University. . 2001c. Overturning Mundell: Fiscal Policy in a Monetary Union. Manuscript, Boston University.

Dixit, Avinash and Luisa Lambertini. 2001. Monetary-Fiscal Policy Interactions and Commitment versus Discretion in a Monetary Union. European Economic Review 45 (4-6, May), 977-87.

Giovannini, Alberto and Luigi Spaventa. 1991. Fiscal Rules in the European Monetary 
Union: A No-Entry Clause. Centre for Economic Policy Research Discussion Paper 516, London, England.

Jones, Mark P., Pablo Sanguinetti, and Mariano Tommasi. 2000. Politics, Institutions, and Fiscal Performance in a Federal System: An Analysis of the Argentine Provinces. Journal of Development Economics 61 (2, April), 305-33.

Kydland, Finn E. and Edward C. Prescott. 1977. Rules Rather Than Discretion: The Inconsistency of Optimal Plans. Journal of Political Economy 85 (3, June), 473-91.

Nicolini, Juan Pablo, Josefina Posadas, Juan Sanguinetti, Pablo Sanguinetti, and Mariano Tommasi. 2000. Decentralization, Fiscal Discipline in Sub-National Governments, and the Bailout Problem: The Case of Argentina. Manuscript, Universidad Torcuato Di Tella, Buenos Aires.

Sibert, Anne. 1992. Government Finance in a Common Currency Area. Journal of International Money and Finance 11 (6, December), 567-78.

Tommasi, Mariano, Sebastian Saiegh, and Pablo Sanguinetti. 2001. Fiscal Federalism in Argentina: Policies, Politics, and Institutional Reform. Economia: Journal of the Latin American and Caribbean Economic Association 1 (2, Spring), 157-200.

Uhlig, Harald. 2002. One Money, But Many Fiscal Policies in Europe: What are the Consequences? Manuscript, Humboldt University, Berlin.

Von Hagen, Jurgen and Barry Eichengreen. 1996. Federalism, Fiscal Restraints, and European Monetary Union. American Economic Review 86 (2, May) 134-38. 